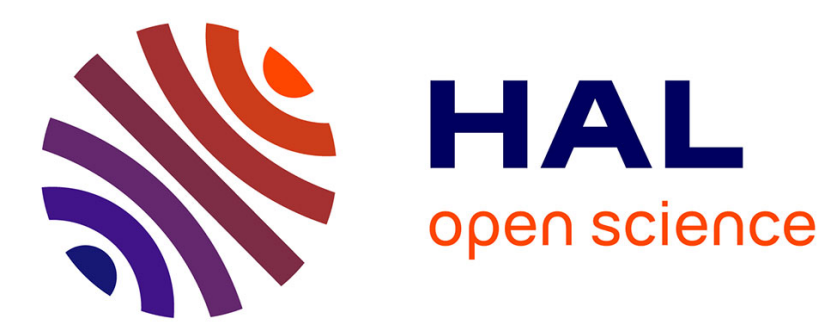

\title{
Technical Change and Total Factor Productivity Growth for Swedish Manufacturing and Service Industries
}

Donghyun Oh, Almas Heshmati, Hans Lööf

\section{To cite this version:}

Donghyun Oh, Almas Heshmati, Hans Lööf. Technical Change and Total Factor Productivity Growth for Swedish Manufacturing and Service Industries. Applied Economics, 2011, pp.1. 10.1080/00036846.2011.564147 . hal-00693831

\section{HAL Id: hal-00693831 \\ https://hal.science/hal-00693831}

Submitted on 3 May 2012

HAL is a multi-disciplinary open access archive for the deposit and dissemination of scientific research documents, whether they are published or not. The documents may come from teaching and research institutions in France or abroad, or from public or private research centers.
L'archive ouverte pluridisciplinaire HAL, est destinée au dépôt et à la diffusion de documents scientifiques de niveau recherche, publiés ou non, émanant des établissements d'enseignement et de recherche français ou étrangers, des laboratoires publics ou privés. 


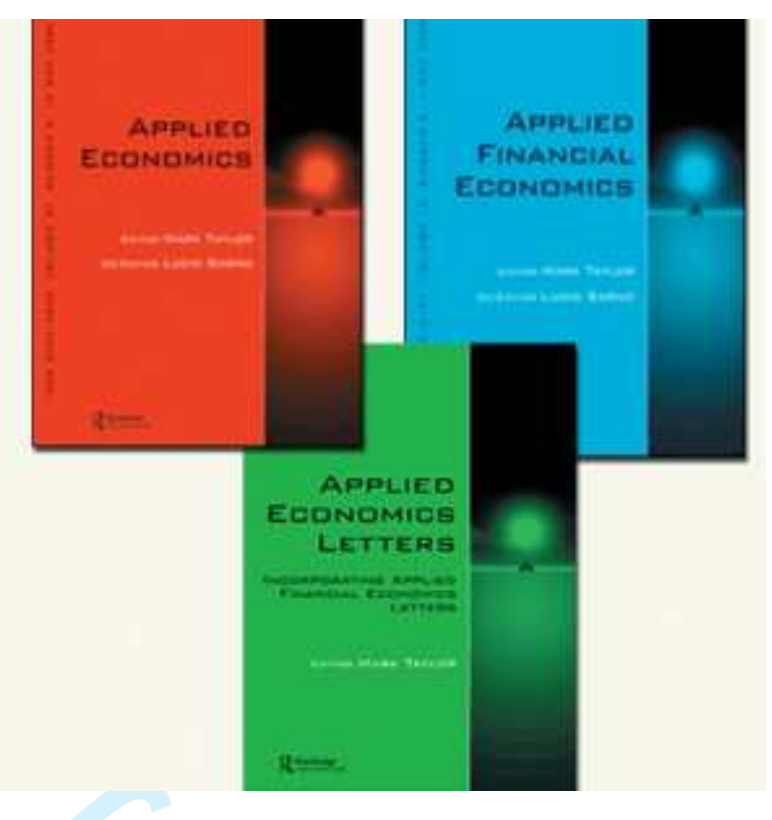

\section{Technical Change and Total Factor Productivity Growth for Swedish Manufacturing and Service Industries}

\begin{tabular}{|c|c|}
\hline Journal: & Applied Economics \\
\hline Manuscript ID: & APE-2009-0546 \\
\hline Journal Selection: & Applied Economics \\
\hline JEL Code: & $\begin{array}{l}\text { C23 - Models with Panel Data \&amp;amp;amp;amp;It; C2 - } \\
\text { Econometric Methods: Single Equation Models } \\
\text { \&amp;amp;amp;amp;It; C - Mathematical and Quantitative } \\
\text { Methods, C52 - Model Evaluation and Testing \&amp;amp;amp;It; } \\
\text { C5 - Econometric Modeling \&amp;amp;amp;It; C - Mathematical } \\
\text { and Quantitative Methods, C67 - Input-Output Models } \\
\text { \&amp;amp;It; C6 - Mathematical Methods and Programming } \\
\text { \&amp;amp;It; C - Mathematical and Quantitative Methods, D24 - } \\
\text { Production|Capital and Total Factor Productivity|Capacity \&amp;It; } \\
\text { D2 - Production and Organizations \&amp;It; D - Microeconomics, } \\
\text { L25 - Firm Size and Performance \&lt; L2 - Firm Objectives, } \\
\text { Organization, and Behavior \&lt; L - Industrial Organization }\end{array}$ \\
\hline Keywords: & $\begin{array}{l}\text { Technical change, Total factor productivity growth, Manufacturing, } \\
\text { Service, Enterprise panel data }\end{array}$ \\
\hline
\end{tabular}




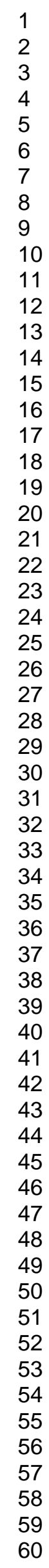

5.) ShholaroNE" $_{\text {Manuscript Central }}$ . 10

25

26

27

29

30

32

33

34

35

36

37

38

41

42

43

45

46

47

48

49

51

52

53

54

55

57

58

59

60 


\title{
Technical Change and Total Factor Productivity Growth for Swedish Manufacturing and Service Industries
}

\author{
Donghyun Oh \\ Centre of Excellence for Science and Innovation Studies \\ Royal Institute of Technology, Stockholm, Sweden \\ E-mail: oh.dongh@gmail.com \\ Almas Heshmati \\ Technology Management, Economics and Policy Program \\ Seoul National University, Seoul, Korea \\ E-mail: heshmati@snu.ac.kr \\ Hans Lööf \\ Centre of Excellence for Science and Innovation Studies \\ Royal Institute of Technology, Stockholm, Sweden \\ E-mail: hansl@infra.kth.se
}

August 29, 2009

\begin{abstract}
This paper presents alternative specifications of the production functions of a large panel of Swedish firms for the period 1992-2000. The period can be characterized as a transition when long-run productivity growth in the Swedish economy improved from being among the weakest to one of the strongest within the OECD. In order to present a detailed exploration of this dramatic change, the time trend and general index models are applied to estimate total factor productivity (TFP) growth, rate of technical change and returns to scale. The models are extended to allow for firm-specific as well as time-varying technical change. The parametric TFP measures are also compared with the non-parametric Solow residual, and several hypotheses are tested to explain the growth patterns in the Swedish economy. It is found that the improved growth rate, initially starting in large exporting manufacturing firms, after a deep economic crisis at the beginning of the 1990s, spilled over to the rest of the economy, both manufacturing and services.
\end{abstract}

Keywords: Technical change, total factor productivity growth, manufacturing, service, enterprise panel data.

JEL codes: C23, C52, C67, D24, L25, L60, L80, O30 


\section{Introduction}

Since the beginning of the 1990s, growth in labor productivity in the Swedish manufacturing sector has been among the highest within the OECD. ${ }^{1}$ Sweden is also considered as a leading innovative country according to the European Innovation Scoreboard (Hollanders and van Cruysen, 2008). The performance of the Swedish economy in recent years is in sharp contrast to the period of stagnation of 1960-1990. From the beginning of the 1960s to the end of the 1980s the average annual growth rate in labor productivity of the manufacturing sector decreased from a high level of 6-7\% to a low level of $1-2 \%$. It is undeniable that falling trend in labor productivity growth was an international phenomenon during the 70 s and 80 s. But Sweden represents an extreme case.

It is well known that sustainable improvement in supply of factors plays an important role in increasing total factor productivity (TFP). The increase in TFP growth yields a high long-run growth of an economy. The supply factors include product and process technology, skill and innovativeness. The gradually deteriorating productivity of the Swedish economy reflects failure in this respect. It also influences the demand side. Notable is that 1/5 of Sweden's international market share was lost between 1977 and 1992 despite a 50\% depreciation of the Swedish krona against the currencies of other key industrialized countries.

This paper examines productivity growth of an Swedish economy during the period between 1992 and 2000. This period constitutes a dramatic change in the Swedish long-run productivity performance and a turning point that coincides with the international recession of 1990-1993. During this three-year period, the average GDP in OECD-Europe grew by only $1.5 \%$. The corresponding figure for Sweden, however, was a 5\% contraction. It was not until 1995 that the Swedish GDP passed the pre-recession 1990-level. Between 1990 and 1993, gross fixed capital formation and employment declined by $27 \%$ and $13 \%$, respectively.

The 1990-crisis started with a dramatic fall in industrial production and many exporting companies faced serious financial problems. However, there were obvious potentials to overcoming the crisis, which includes new technologies, development and implementation of innovations, outsourcing and offshoring available to firms. The recovery in productivity growth started in 1993 and two years later the total manufacturing production was more than $10 \%$ larger despite the substantial reduction in the workforce. ${ }^{2}$

The initial productivity improvement was closely linked to increased demand from the foreign markets and firms' export intensity. Like many other countries, Swedish exports are highly concentrated to a small fraction of firms. Thus, the 20 largest firms account for more than one third of the total export value and multinational firms for $90 \%$ of the exports. Small manufacturing and service firms supplying only on the

\footnotetext{
1 Annual percentage labor productivity growth in manufacturing 1990-2007: Korea 9.1, Sweden 6.1, Taiwan 5.7, U.S. 4.8, Singapore 4.6, France 3.8, Germany 3.7, Japan 3.5, The Netherlands 3.4, U.K. 3.3, Belgium 2.9, Canada 2.6, Denmark 2.4, Australia 2.2, Spain 2.0, Norway 1.7 and Italy 1.5. Source: U.S. Department of Labor.

${ }^{2}$ Within a couple of years employment in the manufacturing sector decreased by $20 \%$.
} 
home-market faced hard conditions because the demand from the home-market contracted by $8 \%$ for the period between 1991 and 1994 .

Based on the above historical overview on the Swedish economy two hyphotheses can be made. One hypothesis to be tested is that large corporations led the productivity improvements in an economy during the period between 1992 and 2000, which yields gradual spillover to other firms and sectors. A second hypothesis is that the potential to increase productivity growth was larger in high technology manufacturing than in low technology firms and services. High technology firms are characterized by extensive R\&D-investments, innovative products, skilled and global labour markets.

Methodologically, we employed a parametric production function approach to examine the TFP growth and its decomposed sources. By decomposing the TFP growth we obtained the rates of technical change, returns to scale and input biases among others. The data consists of 5,893 unique manufacturing and service firms observed during $1992-2000$ and the total number of observations is almost 38,000.

We used various setting-ups in expressing technical change in our models. As a starting point we employed a simple time trend (TT) model in investigating technical change. Since the time trend model has been criticized that a time-trend expression of technical change only represent our ignorance, we also employed the general index (GI) model of Baltagi and Griffin (1988). The two basic models are extended to allow for firm-specific as well as time-varying technical change,each of which yields two extended models. The parametric TFP measures are also compared with the non-parametric Solow residual serving as a benchmark.

The empirical results show that improvements in productivity growth in the Swedish economy were not restricted to large exporting firms. ${ }^{3}$ The positive and high growth rate spilled over to a broad network of manufacturing and service firms irrespective of their size, R\&D and technology intensity. We also investigate determinants of TFP growth as well as the scale properties of the observed firms regarding input elasticities, returns to scale, and input and scale biases calculated from competing models.

The rest of the paper is organized as follows. The theory of productivity analysis is outlined in Section 2. Data on the Swedish manufacturing and service industries are described in Section 3. Section 4 provides the theoretical framework for modelling TFP growth, technical change, input elasticities, returns to scale, and input and scale biases. Section 5 discusses the estimation methods and Section 6 presents the specification tests and empirical results along with a comparison of the performance in the different model specifications. Finally, Section 7 concludes briefly.

\section{The Theory of Productivity Analysis}

It has long been recognized that modeling of production functions plays an important role in analyzing returns to scale, technical change and the rate of total factor productivity (TFP) growth. Attempts in the modelling has been one of the interesting

\footnotetext{
${ }^{3}$ In a previous study on the micro and small Swedish firms, Heshmati (2001) and Johansson (2005) estimate relevant growth measures based on a large firm-level data sets. See also Monte and Pagagni (2003) for for analysis of R\&D and the growth of firms in Italy.
} 
research topics in both theoretical and applied research. Moreover, a rich set of panel data in the field of empirical industrial economics enables sophisticated specifications in modelling production functions.

Due to the great efforts recently devoted to quantifying the rate of TFP growth, technical change and their relevant components, the following four main strands have been built up: (i) econometric estimation of production functions, (ii) the Divisia index, (iii) exact index numbers and (iv) non-parametric methods using linear programming (Diewert, 1981). This section briefly reviews the last three methods. The econometric estimation will be discussed in the next section.

Solow (1957) specifies a general index of technical change as a residual of production activities, in which output is produced by input factors and disembodied technology. In measuring the rate of technical change, three restrictive assumptions are required: constant returns-to-scale, Hicks-neutral technical change and perfect competition. Under these conditions, the rate of technical change is equivalent to the percentage growth in total factor productivity (TFP). The growth rate of TFP can be calculated as the difference in the percentage growth in outputs less the percentage change in a Divisia index of inputs.

Although the Solow residual approach has long been regarded as a pioneering tool for measuring technical change and TFP growth, its assumptions are considered too restrictive. For example, if an economy exhibits increasing returns to scale, the growth in TFP may be attributable to movements along the production function rather than upward shifts in production. The Hicks-neutrality and perfect competition are also considered too restrictive, as discussed in Hulten (2000). Diewert (1976) shows that there exists a class of superlative index numbers which corresponds to various production technologies based on second-order approximation, and that the Tornquivist index, offering a discrete approximation to the Divisia index, is based on a translog technology. By using the translog cost function, it is shown that the percentage change in costs depends on the share-weighted change in input prices. In his approach, increasing, constant and decreasing returns to scale can be assumed. Moreover, the condition of perfect competition can also be relaxed by allowing imperfect competition in input factor markets.

In sum, the Tornqvist index not only provides a very convenient mechanism for measuring technical change without estimating the production function, but also requires fewer assumptions than the Divisia index approach. As indicated by Denny and Fuss (1983), however, the exact index number approach can yield a biased measure for technical change if employed in analyzing industries with increasing returns to scale. They also claim that if the technology is not translog or if the second-order translog parameters differ across firms, the Tornqvist index can result in substantial distortion. When encountering these situations, econometric estimation needs to be employed.

Caves, Christensen, and Diewert (CCD, 1982) provide a non-parametric method using linear programming as an alternative for measuring technical change and TFP growth. By measuring deviations between the benchmarking frontier and decision making units (DMUs), the methods can yield TFP growth rates and their decomposed sources such as efficiency change and technical change. Färe, Grosskopf, Norris and Chang (1994) analyze the TFP growth and technical change of OECD countries for the period between 1979 and 1988, and show that Japan has caught up with the world frontier 
technology and that the US has innovated the world frontier technology. For this, they use the Malmquist productivity index by extending and augmenting the methods of CCD and Nishimizu and Page (1982).

Despite its wide use in measuring TFP growth and its decomposed components, the non-parametric approch also has been criticized for the following reasons: (i) It is not free from outlier problems. Since constructing a benchmarking frontier is highly affected by even a single outlier, TFP and decomposition can be biased. (ii) As Hulten and Isaksson (2007) argue, it suffers from a form of simultaneous equation bias implicit in the endogeneity of capital. A shift in the production function at a given capital-labour ratio leads to an increase in output per worker and some of this extra output is saved, leading to more output, more saving and so on.

\section{The Data}

We used the firm-level panel data, covering the period 1992-2000. The initial data set consists of 39,301 observations on manufacturing and service firms in Sweden. The data is stratified with the sampling conditions based on the representative target population for a national Swedish Innovation Survey conducted in 1999. We have removed the outliers from our data set in order to obtain robust estimation results. The criterion of the truncation is a growth rate of $\pm 80 \%$ of value added. After this truncation, the final data set consists of 37,838 observations for unique 5,893 firms. ${ }^{4}$

Several variables are used in the empirical investigation of the production functions and computation of TFP growth. The value-added of each firm is used as a measure of output $(Y)$. Capital stock and labour ( $K$ and $L$ ) are used as input variables. Capital stock has been computed by the perpetual inventory method, $K_{t}=(1-\delta) K_{t-1}+I_{t}$, where $K_{s}$ and $I_{s}$ are capital stock and amount of investment in time period $s$, respectively. The depreciation rate, $\delta$, is assumed to be constant over the whole period and set at 0.10. Capital stock in the first year, $K_{1}$, is set to be equivalent to the amount of fixed assets. As a measure of labor input $(L)$, we use the number of workers. Value-added and capital stock are deflated by the consumer price index. All the variables are transformed to logarithmic form when estimating the production functions.

The firms are categorized into several groups based on their size and technological levels to investigate the productivity growth patterns stemmed from these firm characteristics. We group them into five size classes by the number of employees: less than 10 (micro), 10-50 (small), 50-100 (small-medium), 100-300 (medium), and over 300 (large) employees. The criteria for the technological levels are obtained from

\footnotetext{
${ }^{4}$ Even though there is no a generally accepted and precise definition of the outlier, it is often referred to as an observation which is inconsistent with the remainder of the set of data (Barnett and Lewis, 1995). Among the reasons for being an outlier, errors when compiling the data set are considered the most likely source. Hence, a robustness can be obtained by removing those errors (or outliers). Quite strict rules for detecting and removing outliers exist in the field of frontier analysis studies, since they play an important role in estimating the models. The approaches of Simar (2003) and Fox, Hill and Diewert (2004) are good examples. The calculation result of TFP growth without the outlier removal can be retrieved from the authors on request.
} 
OECD (2003). The manufacturing firms are categorized into four technological levels: high tech, high-medium tech, medium-low tech and low tech.

Table 1 provides summary statistics of the data for the input and output variables used in this study. The fact that all variables have mean values larger than the median indicates that the distributions of all the variables are skewed to the right. This implies that a large number of firms have operated with small inputs and small output levels and only a few firms have operated with large inputs and large output levels. The skewness of value added, capital stock and labour are 29.1, 28.7 and 26.8, respectively.

The first part of Table 2 gives the descriptive statistics of variables by size. Value added, capital and labour increase as firm size increases. For all the three variables, large discrepancies can be found between large and smaller firms. The average value added of large firms is at least six times larger than that of smaller counterparts. The capital stock and labour of large firms are somewhat larger than those of smaller firms. Although around three quarters of our sample are categorized as small and medium firms, their shares in output labour of the totals are only $32.1 \%$ and $35.4 \%$, respectively.

The second part of Table 2 shows the descriptive statistics of variables by sector and technological level. Nearly $2 / 3$ of the observed firms operate in the manufacturing sector. As expected, the average output of the high-technology manufacturing sector is larger compared to the medium- and low- technology manufacturing sectors.

Table 3 provides descriptive statistics of the variables over time. The mean value added fluctuates and the highest values are attributed to 2000 (93.3) and 1994 (90.9). There is no positive relationship between the level of the mean and its dispersion. The dispersion around the mean value is increasing and highest around 1998-2000. Capital stock also varies over time and reaches its highest values in 1999 and 2000. The dispersion of capital formation around the mean value is similar to that of value added. The change in employment size shows declining pattern. The dispersion in employment is largest during the period 1994-1995 and it reaches its lowest level in 1999.

\section{The Empirical Models}

We used a parametric translog production function to measure the rate of TFP growth and its components. Two specifications, the time trend (TT) and the general index (GI) models, are used as the starting point of the specification of technical change. Despite frequent use of TT and GI models, they still have a drawback in that they do not provide firm-specific measures under the following conditions: (i) If technical change is neutral, (ii) the firms face the same input and output prices. Thus, firm-specific effects in the two models play no role in TFP growth and its decomposition if one of the above conditions arises. The other drawback of the basic TT and GI models is that only intercepts are firm-specific with these specifications. This might not be enough to capture the economically meaningful firm-specific heterogeneity. Hence, implicit restrictions need to be alleviated in order to obtain more flexible modelling of production technology. We alleviated the restrictions imposed on the TT and GI models through their gradual extensions. These extensions generate rates of technical change and TFP growth which are not only time-variant but also input- and firm-specific. The parametric growth measures are further compared with the non-parametric Solow 
residual, which serves as a benchmark.

\subsection{Productivity and technical change}

We assume that production in manufacturing and service industries is specified as the following production function:

$$
Y=f(X, t)
$$

where $Y$ is a scalar output, $X$ is a vector of inputs $(j=1, \cdots, J)$, and $t$ is the time trend variable. Here producers are assumed to maximize output given the inputs and technology available. Taking the total differential of equation (1) gives us the following equation:

$$
\dot{Y}=\sum_{j} \frac{f_{j} X_{j}}{Y} \dot{X}_{j}+\frac{f_{t}}{Y}=\sum \varepsilon_{j} \dot{X}_{j}+\frac{f_{t}}{Y}
$$

where the "dot" over a variable represents its growth rate, $f_{j}$ is a marginal product of the $j^{\text {th }}$ input, and $\varepsilon_{j}$ is the corresponding input elasticity.

Under the assumptions that the firms minimize cost and the input markets are competitive, the relationship in equation (2) can be rewritten as follows:

$$
\dot{Y}-\sum_{j} S_{j} \dot{X}_{j}=\frac{f_{t}}{Y}+(R T S-1) \sum_{j} S_{j} \dot{X}_{j}
$$

where $S_{j}$ is the cost share of input $j$, and $R T S=\sum_{j} \varepsilon_{j}$ is the returns to scale. The left-hand side of equation(3) is referred to as the Divisia index of total factor productivity growth $(T F P)$, expressed as

$$
T F P_{D I V}=\dot{Y}-\sum_{j} S_{j} \dot{X}_{j}
$$

If price data are available, the above TFP growth can be calculated without an econometric estimation. If not, econometric estimation of a production function is necessary.

The main advantage of using a parametric approach over the non-parametric approach of the Divisia index is that one can avoid the strong assumption of constant returns to scale and can decompose TFP growth into technical change $\left(f_{t} / Y\right)$ and scale $\left((R T S-1) \sum_{j} S_{j} \dot{X}_{j}\right)$ components as indicated in equation (3).

\subsection{Time Trend (TT) and General Index (GI) Models}

For illustration of the basic models and their generalizations we assume the following standard specification of a production model with panel data:

$$
y_{i t}=\beta_{0}+\mathbf{x}_{i t} \beta+u_{i t}
$$


where $y_{i t}$ is the $\log$ output of the producer $i \quad(i=1, \cdots, N)$ at time $t \quad(t=1, \cdots, T)$, $x_{i t}$ is the corresponding matrix of $J$ inputs and $\beta$ is $J \times 1$ vector of unknown parameters to be estimated. In this study the error term, $u_{i t}$, is specified as a two-way error component model written as:

$$
u_{i t}=\mu_{i}+\lambda_{t}+v_{i t}
$$

where $\mu_{i}, \lambda_{t}$ and $v_{i t}$ represent firm-specific effects, time-specific effects and statistical noise, respectively. Effects such as advantages or disadvantages in the location of the firm, access to (skilled) labour, measurement errors in the dependent variables and left-out explanatory variables, which cannot be controlled by the producers, are captured by the error term, $v_{i t}$. We assume that this error term is independently and identically normally distributed with zero mean and constant variance, $\sigma_{v}^{2}$. The firm-specific effect, $\mu_{i}$, is a factor representing producer efficiency, and the time-specific effect, $\lambda_{t}$, is a factor representing the exogenous rate of technical change (Heshmati, 2002). In order to avoid over-parameterization of the model the individual firm-specific effects, $\mu_{i}$, are replaced by industry-specific effects, $\eta_{d}$. This accounts for between-industry-specific variations, which are important from a policy perspective. Also, we assume a translog form of the production since it provides a good second-order approximation to a broad class of functions (Kneller and Stevens, 2003).

In the time trend (TT) model, the trend variable is used as a regressor along with the $x$ input variables. The time-specific effect is specified as a linear function of time trend, $t$. Hence, the basic time trend (TT1) model can be written as:

$$
y_{i t}=\beta_{0}+\beta_{t} t+\frac{1}{2} \beta_{t i t} t^{2}+\sum_{j} \beta_{j} x_{j i t}+\frac{1}{2} \sum_{j} \sum_{k} \beta_{j k} x_{j i t} x_{k i t}+\sum_{j} \beta_{j t} x_{j i t} t+\eta_{d}+v_{i t}
$$

where $y$ and $x$ are defined as above, and $t$ is a single time trend representing the exogenous rate of technical change. The $\eta_{d}$ is fixed industry-specific effects to be estimated. We named the model in equation (7) the TT1 model. Our TT1 model is assumed to satisfy the symmetry and convexity conditions.

In the general index (GI) model of Baltagi and Griffin (1998), the trend variable $t$ is replaced by $A(t)$, where $A(t)(t=1, \cdots, T)$ is a vector of time-effects parameters to be estimated. Hence, the corresponding production function assuming the general index representation of technical change is given by:

$$
y_{i t}=\beta_{0}+\sum_{j} \beta_{j} x_{j i t}+A(t)+\frac{1}{2} \sum_{j} \sum_{k} \beta_{j k} x_{j i t} x_{k i t}+\sum_{j} \beta_{j t} x_{j i t} A(t)+\eta_{d}+v_{i t}
$$

where the time trend and its square terms are replaced by $T-1$ fixed time-specific effects $A(t)$. We name the model in equation (8) the GI1 model. The GI1 model is also assumed to satisfy the symmetry and convexity conditions.

Since technical change is defined as the log derivative of output with respect to time $(\partial y / \partial t)$, the rate of technical change (TC) in the TT1 model is given by: 


$$
\mathrm{TC}_{\mathrm{TT} 1}=\beta_{t}+\beta_{t t} t+\sum_{j} \beta_{j t} x_{j}
$$

The corresponding rate of technical change in the alternative GI1 model specification is given by:

$$
\mathrm{TC}_{\mathrm{GI} 1}=\{A(t)-A(t-1)\}\left\{1+\sum_{j} \beta_{j t} x_{j}\right\} .
$$

Technical change expressed in equations (9) and (10) can be decomposed into components associated with pure time-variables (neutral) and input-variables (non-neutral). These components in the TT1 model are $\beta_{t}+\beta_{t t} t$, and $\sum_{j} \beta_{j t} x_{j}$, respectively. In the GI modelthese components are $\{A(t)-A(t-1)\}$ and $\{A(t)-A(t-1)\} \sum_{j} \beta_{j t} x_{j}$, respectively. It is worth noting that there are some problems inherent in the nature of technical change in the TT1 model. First, the rate of technical change either indefinitely increases $\left(\beta_{t t}>0\right)$ or decreases $\left(\beta_{t t}<0\right)$ linearly as a function of time. Second, with unbalanced panel data, it is not clear whether the trend variable, $t$, for a firm entering in period $\tau \quad(1<\tau<T)$ should start from $\tau$ or be replaced with unity. Third, in the case when the time span is relatively narrow, a time trend model might not appropriately represent the exogenous rate of technical change. Finally, the two neutral and non-neutral components of technical change are modelled independently. All of these problems are avoided in the GI1 model by estimating one parameter for each time period in $A(t)$.

Technical change can be biased towards a particular input. This can also be measured. For input $j$, bias $\left(B_{j}\right)$ in technical change is measured by $B_{j}=\partial S_{j} / \partial t$. A positive (negative) value of $B_{j}$ implies that technical change is relatively $j$ th input-using (saving). A zero value of $B_{j}$ indicates that technical change is not biased towards any particular input, i.e., technical change is neutral (Kumbhakar and Hjalmarsson, 1993, and Kumbhakar and Heshmati, 1996). In the TT1 model, $B_{\mathrm{TT} 1, j}=\beta_{j t}$ which is a constant over time, and its sign is simply determined by the sign of $\beta_{j t}$. Hence, input bias in technical change derived from the TT1 model is firm- and time-invariant. In the GI1 model, however, input bias varies over time since $B_{\mathrm{GI} 1, j}=\beta_{j t}[A(t)-A(t-1)]$. This implies that the sign of $B_{\mathrm{GI} 1, j}$ in the GI1 model is determined by the sign of $\beta_{j t}$ and $A(t)-A(t-1)$.

Like the input bias, scale bias in technical change can also be derived from $S B=\partial R T S / \partial t$, where $R T S=\sum_{j} \varepsilon_{j}$. In the TT1 model, the scale bias is given by $S B_{T T 1}=\sum_{j} \beta_{j t}$, while in the GI1 model the scale bias is given by $S B_{G I 1}=[A(t)-A(t-1)] \sum_{j} \beta_{j t}$. The scale bias in the TT1 model is firm- and time-invariant, while in the GI1 model it is time-varying.

Using equations (3) and (9), total factor productivity growth in the TT1 model can be calculated as follows: 


$$
\mathrm{TFP}_{\mathrm{TT} 1}=\mathrm{TC}_{\mathrm{TT} 1}+\left(\mathrm{RTS}_{\mathrm{TT} 1}-1\right) \sum_{j} \varepsilon_{j} \dot{x}_{j},
$$

where $\varepsilon_{j}=\partial y / \partial x_{j}=\beta_{j}+\sum_{k} \beta_{j k} x_{k}+\beta_{j t} t$, and $R T S=\sum_{j} \varepsilon_{j}$. If $R T S$ is greater than (equal to or less than) one, then there are increasing (constant or decreasing) returns to scale. Similarly, TFP growth in the GI1 model can be expressed as follows:

$$
\mathrm{TFP}_{\mathrm{GI}}=\mathrm{TC}_{\mathrm{GI}}+\left(\mathrm{RTS}_{\mathrm{GI}}-1\right) \sum_{j} \varepsilon_{j} \dot{x}_{j},
$$

where $\varepsilon_{j}=\partial y / \partial x_{j}=\beta_{j}+\sum_{k} \beta_{j k} x_{k}+\beta_{j t} A(t)$, and $R T S=\sum_{j} \varepsilon_{j}$.

In the above two TFP growth rate measures, the only difference between TFP growth and technical change is $R T S$. If the production technology exhibits constant returns to scale, then TFP growth rate is identical to the rate of technical change. It should be noted that, if cost shares are available, then TFP growth rate can be obtained using a non-parametric Divisia approach under the assumption of constant RTS.

\subsection{Extensions of Time Trend Model}

Although technical change in the $\mathrm{TT} 1$ model $\left(\mathrm{TC}_{\mathrm{TT} 1}\right)$ is firm- and time-specific because input variables vary across firms, technical change is not firm-specific when the components related to input variables are all zero. It is important to obtain firm-specific neutral components. In this sense, The restrictive feature can be removed by extending the TT1 model in much more flexible ways. . Using the model proposed by Cornwell, Schmidt and Sickles (1990), the extended time trend model (hereafter, TT2 model) can be specified as:

$$
y_{i t}=\beta_{d t}+\sum_{j} \beta_{j} x_{j i t}+\frac{1}{2} \sum_{j} \sum_{k} \beta_{j k} x_{j i t} x_{k i t}+\sum_{j} \beta_{j t} x_{j i t} t+v_{i t},
$$

where $\beta_{d t}$ denotes industry- and time-specific intercepts. By replacing $\beta_{d t}$ with a flexible parametric function of time, the TT2 model considers the industry-specific effects inherient in technical change. The model for the intercept $\left(\beta_{d t}\right)$ given in this study is specified as follows:

$$
\beta_{d t}=\eta_{1 d}+\eta_{2 d} t+1 / 2 \eta_{3 d} t^{2}
$$

where $\eta_{1 d}, \eta_{2 d}$ and $\eta_{3 d}$ are unknown industry-variant parameters to be estimated. Hence, in the above specification $\beta_{d t}$ is a quadratic function of time trend and varies across industries. The temporal pattern of $\beta_{d t}$ is flexible and no further assumption is required. Technical change in the TT2 model is expressed as follows:

$$
\mathrm{TT}_{\mathrm{TT} 2}=\eta_{2 d}+\eta_{3 d} t+\sum_{j} \beta_{j t} x_{j} .
$$

Thus, $T C_{T T 2}$ is industry-specific and it also changes over time even when all input variables are zero. The pure component of technical change $\eta_{2 d}+\eta_{3 d} t$ is both industry-specific and time variant. However, the industry-specific effects are not 
incorporated in the non-neutral technical change component, $\sum_{j} \beta_{j t} x_{j}$. In the same way as before, total factor productivity growth of the TT2 model can be obtained from:

$$
\mathrm{TFP}_{\mathrm{TT} 2}=\mathrm{TC}_{\mathrm{TT} 2}+\left(\mathrm{RTS}_{\mathrm{TT} 2}-1\right) \sum_{j} \varepsilon_{j} \dot{x}_{j},
$$

where $\operatorname{RTS}_{\mathrm{TT} 2}$ and $\varepsilon_{j}$ are returns to scale and elasticity of input $j$, respectively.

Although the TT2 model is successful in making the pure component of technical change industry-specific, non-neutral technical change is still restrictive as in the TT1 model. Now, we consider another extension of the TT2 model, the TT3 model, which allows industry-specific non-neutral technical change. The production function in the TT3 model is expressed as:

$$
y_{i t}=\beta_{d t}+\sum_{j} \beta_{j} x_{j i t}+\frac{1}{2} \sum_{j} \sum_{k} \beta_{j k} x_{j i t} x_{k i t}+\sum_{j} \zeta_{j d} x_{j i t} t+v_{i t},
$$

where $\beta_{d t}$ is the same as in the TT2 model, $\zeta_{j d}(j=1, \cdots, J)$ are industry-specific unknown parameters to be estimated.

Technical change from the TT3 model is given by:

$$
\mathrm{TT}_{\mathrm{TT} 2}=\eta_{2 d}+\eta_{3 d} t+\sum_{j} \zeta_{j d} x_{j}
$$

TFP growth of the TT3 model is the same as in equation (16) except that the subscript TT2 is replaced with TT3.

Input bias and scale bias in the TT2 model are the same as in the TT1 model. Input bias and scale bias in the TT3 model, however, are industry-specific. For input $j$, $B_{\mathrm{TT} 3, j}=\zeta_{j d}$. Its sign is simply determined by the sign of $\zeta_{j d}$. Scale bias is expressed as $S B_{T T 3}=\sum_{j} \eta_{j d}$.

\subsection{Extensions of General Index Model}

Under the specification of the GI1 model an implicit restriction on the temporal pattern of technical change across industries is imposed. This means that technical change varies over time but it is the same across different industries if the components related to the input variables are all zero. This undesirable feature of invariant technical change across industries can be removed in such a way that the rate of technical change is industry-,time- and firm-specific. We have eliminated the restriction in two ways. In the first extended model, GI2, following Lee and Schmidt (1993), we make pure technical change industry-specific by specifying the production function as follows:

$$
y_{i t}=\eta_{d} A(t)+\sum_{j} \beta_{j} x_{j i t}+\frac{1}{2} \sum_{j} \sum_{k} \beta_{j k} x_{j i t} x_{k i t}+\sum_{j} \beta_{j t} x_{j i t} A(t),
$$

where $\eta_{d}$ denotes industry-specific parameters. In equation (19) two vectors, $\eta_{d}$ and $A(t)$, are unknown parameters to be estimated. Thus, technical change in the GI2 model is expressed as: 


$$
\mathrm{TC}_{\mathrm{GI} 2}=\eta_{d}[A(t)-A(t-1)]+\sum_{j} \beta_{j t} x_{j}[A(t)-A(t-1)]
$$

In equation (20), the industry specific effect is inherent in the pure component of technical change, $\eta_{d}[A(t)-A(t-1)]$. The non-neutral component of technical change is $\sum_{j} \beta_{j t} x_{j}[A(t)-A(t-1)]$. Note that industry-specific effects are not incorporated in the non-neutral component of technical change of the GI2 model. However, the two components are not independent, implying that no non-neutral technical change can take place without attaining a pure rate first. Also note that, unlike the extensions of time trend models, no functional form of technical change is assumed, which is useful and reasonable when the time span of panel data is narrow.

The GI2 model can be further extended when every $A(t)$ in equation (8) is replaced by industry-specific general indexes. The production function in the GI3 model is expressed as

$$
y_{i t}=\eta_{d} A(t)+\sum_{j} \beta_{j} x_{j i t}+\frac{1}{2} \sum_{j} \sum_{k} \beta_{j k} x_{j i t} x_{k i t}+\sum_{j} x_{j i t} \zeta_{j d} A(t)
$$

where $\zeta_{j d}$ denotes unknown parameters to be estimated. The rate of technical change in the GI3 model is obtained as:

$$
\mathrm{TC}_{\mathrm{GI} 3}=\eta_{d}[A(t)-A(t-1)]+\sum_{j} x_{j} \zeta_{j d}[A(t)-A(t-1)]
$$

The GI3 model is much more flexible than the GI1 or GI2 models in that the industry-specific effects are inherent in both the pure component and the non-neutral component of technical change.

Input bias and scale bias in the GI2 model are the same as in the GI1 model. In the GI3 model, however, input bias and scale bias are industry- and time-specific. These measures are obtained as:

$$
\begin{aligned}
& B_{\mathrm{TT} 3, j}=\zeta_{j d}[A(t)-A(t-1)] \\
& B S_{\mathrm{TT} 3}=\sum_{j} \zeta_{j d}[A(t)-A(t-1)] .
\end{aligned}
$$

\subsection{The Non-parametric Approach}

This sub-section provides a traditional measure of the TFP growth rate, the Solow residual approach. We begin with the following production function:

$$
Y=A f(K, L),
$$

where $A$ is a Hicks neutral technology index, which allows for shifts of the production function. By totally differentiating equation (24) and dividing it by $Y$, we have the following growth equation:

$$
\dot{Y} / Y=\varepsilon_{k} \dot{K} / K+\varepsilon_{l} \dot{L} / L+\dot{A} / A,
$$

where $\varepsilon_{k}$ and $\varepsilon_{l}$ represent elasticities of output with respect to capital and labour. By 
assuming constant returns to scale, $\varepsilon_{l}$ can be replaced with $1-\varepsilon_{k}$ and equation (25) can be expressed as follows:

$$
S R=\dot{Y} / Y-\left(1-\varepsilon_{k}\right) \dot{L} / L-\varepsilon_{k} \dot{K} / K,
$$

where the Solow residual $S R$ is equivalent to the estimate of TFP growth, represented by $(\dot{A} / A)$. It is often considered as a benchmark in empirical studies.

\section{Estimation Methods}

In panel data literature, the estimation processes of error component models shown in equations (7), (13), (17), (8), (19) and (21) have been developed in different directions. Applying a static formulation, as in our case, the models are mainly estimated using fixed and random effects. The fixed effects (FE) model assumes that $\mu_{i}$ and $\lambda_{t}$ are fixed and correlated with the explanatory variables, while in the random effects (RE) model both error terms are assumed to be purely random. Efficiency, unbiasedness and consistency are the properties affecting the choice of FE and RE models.

We employ the following steps for choosing an appropriate estimation process: (a) in TT1 and GI1 models, the industry-specific intercepts, $\eta_{d}$, are substituted by firm-specific intercepts, $\eta_{i}$, (b) the least-squares dummy variables (LSDV) method and the maximum likelihood estimation (MLE) method are employed in estimating the two models with FE and RE, respectively, (c) The Hausman test is applied to choose an appropriate estimation process for both of the model specifications, and (d) the chosen estimation processis assumed to be applicable to the extended models.

The assumption in (d) above is necessarily imposed due to the fact that (i) with many observations in our data set, it is quite a time consuming task if firm-specific intercepts, $\eta_{i}$, are incorporated in the non-linear model specifications such as the GI2 and GI3 models, and (ii) with our large data set, observing fixed effects of individual firms is not meaningful. The above strategy reduces the excessive number of firm-specific unique parameters and is employed in estimating all the six models. One loss is the within-industry variation, but it maintains the between-industry variations. The amount of information loss is reduced by appropriate classification of industries such that it is useful for policy analysis.

Results of the Hausman test signify that the FE model captures the nature of our data set better than the RE model. Hence, we use only the FE-type models when calculating the components of TFP growth and reporting the results. The TT1, TT2, TT3 and GI1 models are linear and estimated using LSDV methods, while GI2 and GI3 models are nonlinear and estimated by MLE methods. In each model, we assume that $v_{i t} \square$ i.i.dN $\left(0, \sigma_{v}^{2}\right)$,independent of the explanatory variables.

As discussed above, industry dummy variables are included to capture industry-specific features of TFP growth and rate of technical change. Fifteen industry dummy variables are used for this purpose, eleven of which are manufacturing sectors and four of which are service sectors. The classification follows the international industrial classification system, which is listed in the Appendix. 


\section{Empirical Results}

\subsection{Specification Tests and Model Selection}

The six model specifications (TT1, TT2, TT3, GI1, GI2 and GI3) presented in Section 5 are used to estimate the productivity growth and its decomposed components of Swedish firms for the period 1992-2000. In all the models the null hypothesis of constant returns to scale is rejected in favour of variable returns to scale at the $1 \%$ level of significance. It suggests that a parametric approach to TFP measurement is to be preferred to the Solow residual approach. The $R^{2}$ values are quite high, around 0.9, in all the models. Due to the large size of parameters estimated and rejection of some models by a model selection procedure described below, the estimates of the parameters of the models are omitted from this paper in order to save space 5 .

Although different assumptions of behaviour of technical change are inherent in each of our six models, it is essential to take into consideration which of these six competing models are appropriate for our data set and whether the corresponding results from such models are reasonable or not. One main obstacle to choosing appropriate models is that our six models are not nested in a single super model. The TT1 is nested in the TT2 and TT3, and the TT2 is nested in the TT3. The GI1 is not nested in the GI2 or GI3, whereas the GI2 is nested in the GI3. Furthermore, the TT models are not nested in the GI models, and vice versa. Because of this, we perform two non-nested tests ( $\mathrm{J}$ test and Cox test) to examine the appropriateness of different non-nested models. For the nested models, we use a log-likelihood ratio test (LR test) for choosing appropriate models.

The result of the LR test on the TT1 and TT2 models rejects the TT1 at the 1\% level of significance in favour of the TT2. The results of the LR test on the TT2 and TT3 models reject the TT2 in favour of the TT3. Thus, the test results give us conclusive evidence that the TT3 is the best model among time trend model specifications.

As discussed above, the GI1 is not nested with the GI2. The results of J test and Cox test show that the GI1 is preferred to the GI2, and the GI2 is not preferred to the GI1. However, the J test and the Cox test on the GI1 and GI3 models show that neither of the models is preferred. This is quite a well known problem with the $\mathrm{J}$ test and the Cox test and is not necessarily associated with our model specification or data set. The LR test on the GI2 and GI3 models shows that the GI2 is rejected at the $1 \%$ level of significance in favour of the GI3 model. Hence, among the GI models, the GI1 and GI3 are chosen as being the best models for describing our data.

In a final step, we test the preferred time trend model, TT3, against the two GI models, GI1 and GI3. The J test and the Cox test on these model selections are inconclusive. Then, we test each of the two GI models against the TT3 model, the results of which also yield inconclusiveness. Thus, these tests do not help us to choose the single best model among the TT3, GI1 and GI3 models.

Although the above statistical methodologies does not enable us to select a better model between the two GI models, the rationale extending the basic GI model (GI1) to the GI2 and then to the GI3 helps us to choose an appropriate model in a heuristic manner.

\footnotetext{
${ }^{5}$ Interested readers can obtain the estimation results of the six models from the authors.
} 
Since the industry-specific technical change is included in the GI2 and the GI3 models and the GI3 produces a better fit than the GI2, we conjecture that the GI3 is more appropriate than the GI1. In the following our presentation is mainly focused on the results of the TT3 and GI3 models. The complete estimates can be obtained from the authors.

\subsection{Input Elasticities and Returns to Scale}

The elasticities of output with respect to each of the inputs of capital and labour, $\varepsilon_{j}$, are calculated from $\varepsilon_{j}=\partial y / \partial x_{j}$, which measures the percentage changes in output in response to the percentage changes in inputs. The returns to scale (RTS), measuring changes in output in response to proportional changes in all inputs, are calculated from the sum of the two input elasticities. These input elasticities and returns to scale vary over time and across firms.

In Table 4 we report elasticities and RTS with respect to year of observation, industrial sector, firm size, and technology classification for the whole sample. Since the t-statistics based on the estimated elasticities and their standard errors are over 2, the hypotheses of zero input elasticities are rejected for inputs in both models.

The capital elasticities of the TT3 and GI3 models are 0.197 and 0.193, respectively. The corresponding labour elasticities are 0.816 and 0.821 , respectively. The fact that the labour elasticity is larger than the capital elasticity reflects the fact that the increase of labour is more effective than the increase of capital in producing more output. However, both models show that the capital intensity increased somewhat between 1992 and 2000. Returns to scale of the two models are almost identical, indicating that the production technology exhibits increasing returns to scale. Returns to scale of the two models are almost identical, 1.010 and 1.011 for TT3 and GI3, respectively. The fact that RTSs of the two models are larger than unity signifies that the production technology exhibits increasing returns to scale. On average, Swedish firms in our sample are found to be of sub-optimal size.

In the upper part of Table 4, both models reveal a tendency for the capital elasticity to increase over time, while the trend is the opposite for labor elasticity. The mild downturn in the business cycle in the mid 1990s is reflected in a temporary decrease of RTS in the TT and the GI models. Notable is that the time trend model reports a growing RTS during the observed period. This trend cannot be found in the GI model.

Looking at the elasticities and RTS by industries, it is found that the input elasticities differ considerably across models but are mostly of reasonable sizes. ${ }^{6}$ Compared to services, manufacturing firms generally have higher capital elasticity, lower labour elasticity and higher returns to scale.

The relationships between the sizes and elasticities are also presented in Table 4. A priori, one would expect the degree of capital utilization to increase as the size of a firm increases. This is confirmed by the empirical results. By contrast, labour elasticities decrease as the size of a firm increases. These trends suggest that it is

\footnotetext{
${ }^{6}$ Acronyms of industries are provided in the Appendix.
} 
relatively more efficient for smaller firms to exploit the labour force rather than the capital stock, and vice versa for larger firms. Another interesting finding is that the returns to scale correlate positively with firm size. Only small firms operate close to their technically optimal size. Both models indicate that micro firms operate below their optimal scale of production while small-medium, medium or large firms have the potential to increase their efficiency by adjusting their scale downwards.

The average capital elasticity among firms belonging to the R\&D and human-capital-intensive high technology is lower than for other firms and the labour elasticity is higher. This result, shown in both models, indicates the particular importance of well-educated, well-trained and skilled workers for value added activities in knowledge intensive firms. In firms characterized by standardized production it is more efficient to substitute workers with machines.

\subsection{Rate of Technical Change}

Technical change is reflected in a neutral shift in production function as a result of technological advancement for given input utilization. A positive rate indicates technical progress like improvement of production processes and learning by doing, while a negative rate of technical change indicates technical regress. Table 5 reports results for the TT3 and the GI3 models.

The average rates of technical change in all the models are positive, indicating technical progress. The overall mean rate of technical change is almost the same for all the models, around 2\% per year increase in the level of output for given level of inputs used in production. Although figures are not tabularzed in this paper, it is found that there is a systematic difference between all the TT models and the GI models. all the TT models have a downward trend, explained by a reduced growth rate of the pure technical change. No corresponding pattern can be found among the GI models.

In the TT3 model, the overall mean rate of technical change decreased during the study period. Since the pure technical change continuously decreased and the non-neutral technical change is negligible the decreasing trend of technical change is mainly influenced by the pure technical change. In the GI3 model, instead of showing a smooth uniform pattern, the rate of technical change fluctuates during the study period. Although the rate of technical change was decreasing in 1996 influenced by the a mild cyclical downturn, it rapidly began to regain a favourable rate of growth. An obvious pattern cannot be found in the relationship between the pure technical change and the non-neutral technical change components.

The rates of technical change averaged by each of industrial branches are also listed in Table 5. The extent of technical change varies somewhat across industries, ranging from close to zero percent in the food industry to above $3 \%$ in machinery and equipment. However, the majority of industries (11 in the TT-model and 14 in the GI-model) have a growth rate above $1 \%$. Contrary to our expectation, no systematic link is found between firms belonging to an export-oriented industry and technological change.

Turning now to the technical change relating to the size, if one ignores the fact that the estimates for micro firms are somewhat deviating (1.3) in the GI3 model, the results are very close (1.8-2.1) for small, small-medium, medium and large firms. The rate of 
technical change is almost identical for all size classifications in the TT3 model. Hence, we find no evidence supporting the hypothesis of superior technological advancement in large firms.

This paper also studies the relationship between the rate of technical change and technology classification. Looking first at manufacturing versus services, the rates of technical change are almost the same in the TT3 model, while the GI reports $2.1 \%$ for manufacturing and $1.6 \%$ for services.

Consider then manufacturing firms were classified into four different classifications according to technology intensity defined by R\&D and human capital. A priori one would expect the positive relationship between the technology intensity and technical change since technological advancement is mainly led by technology-intensive industries. This is partly confirmed by the results. The TT3 model shows that the magnitude of the technological change is lower in low and medium-low tech firms than in high tech and high-medium tech firms. However, in the GI3 model no difference can be found among the high, medium-low and low technology industries. The annual growth rate of these industries is about $2 \%$. The corresponding figure for the typical high-medium technological firms is $2.6 \%$.

\subsection{Technological Bias Effects}

Technological change can be biased towards certain inputs or have different impacts on different factors such as the wages of labour of different skills. Such change will induce changes in the proportion of inputs used in production. A negative sign indicates input-saving, while a positive sign indicates input-using technological change. The sum of the input biases is labelled as scale bias. Unlike returns to scale, which are the sum of expected positive input elasticities, the scale bias might turn out to be zero as a result of different input biases with opposite signs cancelling out each other when summed.

The overall capital and labour biases for all six models are presented in Table 6 . Note that the standard deviation of input and scale biases of the TT1 and TT2 models are constant for all firms over time (See the first and second rows) This is due to the inflexible way they are specified.

In general, the results are very much model-dependent. The patterns of factor using/saving biases are similar for five of the models except for the GI2 model. These five models show capital saving and labour using patterns. Compared to the TT3 model, the factor biases in the general index models vary widely across models.

The mean scale bias is also listed in Table 6. Note that the standard deviation of scale bias is zero by definition in the TT1 and TT2 models. Like the average input biases, the average rate of scale bias vary substantially among the competing models. The GI 2 model has quite large scale bias, while the other models yield similar figures that are significantly different from zero (around $2 \%$ ). It needs to be noted that although the magnitudes of the scale bias are comparably small in the other five models, due to cancellation effects, they are not necessarily irrelevant to the productivity growth. 


\subsection{Total Factor Productivity Growth}

Table 7 presents the rate of total factor productivity (TFP) growth for all six models. The Solow residual approach is also presented in the table for comparison purposes.

The TFP growth over time, and by industrial branch, firm size, and technological levels are reported as sample means. See the bottom part of the table. The rate of TFP growth is almost identical in the GI models (around 2\% per year). The corresponding figures for the TT models and the Solow residual are 1.3-1.5\%. The result for all models shows a considerable improvement in TFP-growth compared to the period before the economic crisis in Sweden in the beginning of the 1990s. Comparing the result of the technical change with the TFP growth, it can be found that patterns of the rate of TFP growth in all the six models are very much similar to those of the technical change component. This implies that the main mechanism for the change in productivity growth is technical change.

Looking at the TFP growth by year, the upper part of Table 7 reports a systematic difference between the time trend models and the other two models. The TT models yield decreasing trends in the rate of TFP growth, whereas the rate of TFP growth of GI models does not show any trend pattern. The result of the Solow residual is similar to those of GI models. Both of the GI models and Solow residual reveal a slower growth rate in the middle of the observed period, coinciding with a cyclical downturn in the economy.

Interestingly, the results of the TT, GI and Solow residual of the productivity equations by industry suggest a common feature of relatively high growth rate in the Swedish economy during the 1990s. This finding coincides with the rate of technical change, discussed above. Though the growth rates differ among the specifications, our two preferred models, TT3 and GI3, show conflicting results only for a few industries. The TFP growth for the 15 different industries are mainly explained by technical change in both the time trend and the general index models.

The hypothesis that $R \& D$ investments are particularly important for high and sustainable growth in productivity has been suggested at a theoretical level by many authors, arguing that there is close linkage among R\&D activities, technical change, innovation, competitiveness, market size and productivity. Since large manufacturing firms and high technology firms are considerably more R\&D-intense than other firms, one would expect a systematic difference in TFP growth in our sample. Looking at the relationship between productivity growth and firms' size, the hypothesis is confirmed by the non-proffered TT and GImodels. However, the TT3 model reports high growth rates for micro (1.6\%), small (1.3\%), small-medium $(1.6 \%)$ medium $(1.8 \%)$ and large firms $(2.1 \%)$. The correlation between size and productivity growth is even more narrow in the GI3 model; the range between micro and large firms is $1.8 \%-2.2 \%$. No systematic relationship at all between these variables is shown in the Solow residual approach. We also see that the link between a manufacturing firm's technology intensity and TFP growth is non-existent. Moreover, our expected difference in TFP growth between manufacturing firms and services is not strongly supported by the results. Only the GI3 model and the Solow residual report larger growth rates for manufacturing firms. 


\subsection{Determinants of TFP Growth}

We now identify different growth determinants of TFP growth and estimate their importance. The information aims to increase our understanding of conditions for firms' survival, profitability and growth. A total of six indicators are identified and used in the regression analysis. These are: capital intensity (CAPINT), market competitiveness (MKTCOM), human capital (HMNCAP), growth in human capital (HMNGRT), capital structure (CAPSTR) and wage growth (WGGRTH).

Firms with a higher level of capital intensity, where capital intensity is considered as a measure of the firm-specific knowledge embodied in the machinery and equipment in production, are expected to have high asset specificity and thereby potentially more variability in capital utilization. The possibility of increase in the rental cost of unused capital encourages firms to use their production resources efficiently (Jung, 1991). However, empirical studies show a somewhat mixed strand of the results for this hypothesis. For example, Lim (1980) and Sheehan (1997) give support to the positive relationship between the level of capital intensity and the firms' performance, whereas Ferrier, Klinedinst and Linvill (1998) and Mahadevan and Kalirajan (2000) report a negative effect of capital intensity on production. We measure the capital intensity of a firm by the ratio of capital to the number of employees and its growth rate is used as one of the determinants of productivity growth.

Regarding the relationship between the performance and the competitive condition of a market, two different points of view exist in the literature. Neoclassical economists support a positive association between the two measures arguing that the elimination of slacks promotes performance. In contrast, Schumpeterians and others assert a negative relationship, pointing out that monopoly rents induce entrepreneurs to invest in $R \& D$ activities and thus promote dynamic performance. In empirical tests, Nickell (1996), Aghion, Harris, Howitt and Vickers (2001) and Boone (2001) find some support for the view that competition improves performance, whilst Dasgupta and Stiglitz (1980) support the Schumpeterian view. In this paper, competition is measured by the Herfindahl index, $\sum_{i} s_{i}^{2}$, where $s_{i}$ is the market share of $i^{\text {th }}$ firm. It should be noted that a Herfindahl index close to unity indicates a less competitive market condition.

Human capital is widely recognized as an important source of economic growth. Modern growth theories such as those of Romer (1986) and Lucas (1988) emphasize how human capital can stimulate economic growth through technological development, uptaking and imitation of new technologies, invention and innovation. Yet, adequately measuring its stock at various levels of aggregation remains controversial. Three general approaches to human capital measurement are education-based, cost-based and income-based (For a literature review, see Le, Gibson and Oxley, 2005). Following the empirical neo-Schumpeterian, we use formal education as a proxy for human capital. Our observed measure is the number of employees who have at least a bachelor's degree in engineering or science studies, and we distinguish between level and growth rate of human capital. There is a vast empirical literature verifying a positive and statistically significant relationship between human capital and productivity and between R\&D and productivity as well. Since the definition of human capital in this paper also includes R\&D personnel, a positive correlation across firms can be expected. Klette and Kortum (2004) report, however, that the longitudinal (within firm, and across time) relationship between firm-level differences in $R \& D$ and productivity 
growth is often low and insignificant.

Corporate governance defines the ways in which the supplier of finance to corporations is assured of getting a return on investment in a firm. Various stakeholders such as debt holders, equity holders and their representatives define the firm's rules, incentives and goals. Capital and resources are efficiently allocated by these activities (Kim, 2006). Hence, the structure of corporate governance is often closely linked to the growth of a firm and productivity. In our case, the corporate governance is to be captured by the capital structure of firms, which is defined as the ratio of debt to total.

We also examined the relationship between wage costs and TFP growth. Considering that firms' labour demand is mainly determined by labour productivity, it is likely that wages will increase if an employee is more productive. We therefore expect a positive correlation between the wage growth and the growth of TFP.

In order to isolate the relationships between the above six variables and TFP growth, it is essential to control for other factors that are likely to affect TFP growth. This is important for dealing with the heterogeneity of the firms in our sample. Among the various firm-specific attributes that are shared by firms in our sample, we have chosen the following control variables: firm size dummy, year dummy and industry dummy variables.

Table 8 presents the fixed effects parameter estimates of the determinants of TFP growth. Somewhat surprisingly, all six models show a negative relationship between capital intensity and TFP-growth. One possible explanation is that a considerable fraction of the capital stock became obsolete during the 1990s, a period characterized by rapid technological change due to ICT and other new technologies.

Regarding the market competition, signs as well as significant levels differ across model specifications. Only the results of the time trend models support the hypothesis that higher competition increases the TFP growth.

Our expression of human capital as university educated employment is positively and highly significantly related with TFP growth at the level dimension in all six models. However, we find the link between growth in education and growth in TFP to be fragile. Only the GI3 model indicates that TFP is influenced by both the stock and flow of human capital.

The capital structure variable displays a positive coefficient in the TT1, TT2, TT3, GI1 and GI2 models, while the GI3 model yields a negative coefficient. None of the coefficients, however, are statistically different from zero.

Finally, we can observe a positive and statistically significant relation between wage growth and TFP growth among all the model specifications. Since we control for level of education, the growth of wages reflect the fact that the average employee has become more productive due to factors such as learning by doing, more efficient methods of organizing the work, outsourcing and downsizing of less productive activities.

\section{Summary and Conclusions}

This paper presents a detailed exploration of technical change and total factor 
productivity (TFP) growth of a large panel of Swedish manufacturing and service firms over the period 1992-2000. The period is characterized as a transitional one in which the long-run productivity growth in Swedish manufacturing improved from being among the weakest to one of the strongest within the OECD.

One hypothesis tested is that the initial productivity improvements in manufacturing industries dominated by large multinational corporations are gradually spilled over to other firms and sectors through supply links and other forms of networking, new technology, development and implementation of innovations and outsourcing.

A second hypothesis is that $R \& D$ investment is particularly important for high and sustainable productivity growth due to its impact on technological change, innovation, competitiveness and market size. Since large manufacturing firms and high technology firms are considerably more R\&D-intense than other firms, we expect a systematic difference in TFP growth in our sample.

Methodologically, we employed a parametric production function approach. We analyzed the TFP growth and investigated the decomposed components such as the rates of technical change, returns to scale and different input biases. The time trend and general index models were extended to allow for firm-specific as well as time-varying technical change. The results were compared with the non-parametric Solow residual.

The results of model selection tests are somewhat mixed. However, the heuristic inherent in extending the basic models and the results of comparing with the non-parametric Solow residual approach help us to choose the best model among the six models. Amoht the six models, the GI3 model were chosen as the best model in describing our sample data.

The empirical results show that improvements in long-run productivity growth in the Swedish economy are not restricted to large exporting manufacturing firms and high technology firms. The positive and high growth rate is spilled over to a broad network of manufacturing and services firms irrespective of their size and technology intensity. Hence, the transition process towards an increased rate of productivity growth is a phenomenon that permeated the whole Swedish economy during the 1990s. The main mechanism for development was the increased rate of technical change. 


\section{References}

Aghion, P., Harris, C., Howitt, P., Vickers, J., 2001. Competition, imitation and growth with step-by-step innovation. Review of Economics Studies 68, 467-492.

Anon Higon, D., forthcoming. The impact of R\&D spillovers on UK manufacturing TFP: A dynamic panel approach. Research Policy.

Baltagi, B. H., Griffin, J. M., 1988. A general index of technical change. The Journal of Political Economy 96(1), 20-41.

Barnett, A., Lewis, T., 1995. Outliers in Statistical Data. Chichester: Wiley.

Boone, J., 2001. Intensity of competition and the incentive to innovate. International Journal of Industrial Organization 19, 705-726.

Caves, D. W., Christensen, L. R., Diewert, W. E., 1982. The Economic Theory of Index Numbers and the Measurement of Input, Output, and Productivity. Econometrica 50 (6), 1393-1414.

Cornwell, C., Schmidt, P., Sickles, R. C., 1990. Production frontiers with cross-sectional and time-series variation in efficiency levels. Journal of Econometrics 46(1-2), 185-200.

Dasgupta, P., Stiglitz, J., 1980. Industrial structure and the nature of innovative activity. Economic Journal 90, 266-293.

Denny, M., Fuss, M., 1983. A general approach to intetemporal and interspatial productivity comparison. Journal of Econometrics 23 (3), 315-330.

Diewert, W. E., 1976. Exact and superlative index numbers. Journal of Econometrics 4 (2), 115-145.

Diewert, W. E., 1981. The theory of total factor productivity measurement in regulated industries. Academic Press, New York.

Ferrier, G. D., Klinedinst, M., Linvill, C. B., 1998. Static and dynamic productivity among Yugoslav enterprises: Components and correlates. Journal of Comparative Economics 26(4), 805-821.

Färe, R., Grosskopf, S., Norris, M., Zhang, Z., 1994. Productivity growth, technical progress, and efficiency change in industrialized countries. Americal Economic Review 84 (1), 66-83.

Fox, K. J., Hill, R. J., Diewert, W. E., 2004. Identifying outliers in multi-output models. Journal of Productivity Analysis 22 (1) 73-94.

Heshmati A., 2001. On the Growth of Micro and Small Firms: Evidence from Sweden. Small Business Economics 17(3), 213-228.

Heshmati, A., 2002. Productivity measurement in Swedish departments of gynecology and obstetrics. Structural Change and Economic Dynamics 13(3), 315-336.

Hollanders H., A. Van Cruysen, A., 2008. Rethinking the European Innovation Scoreboard: A New Methodology for 2008-2010. Pro Inno Europe Innometrics.

Hulten, C. R., 2000. Total Factor Productivity: A Short Biography. NBER working paper series 7471. National Bureau of Economic Research, MA. 
Hulten, C. R., Isaksson, A., 2007. Why development levels differ: The sources of differential economic growth in a panel of high and low income countries. NBER working paper series 13469. National Bureau of Economic Research, MA.

Jerzmanowski, M., forthcoming. Total factor productivity differences: Appropriate technology vs. efficiency. European Economic Review.

Johansson, D., 2005. The Turnover of Firms and Industry Growth. Small Business Economics, 24(5): 487-495.

Jung, Y., 1991. Multinationality and profitability. Journal of Business Research 23(2), 179-187.

Kim, E., 2006. The impact of family ownership and capital structures on productivity performance of Korean manufacturing firms: Corporate governance and the "Chaebol problem". Journal of the Japanese and International Economies 20(2), 209-233.

Klette, T. J., Kortum, S., 2004. Innovating Firms and Aggregate Innovation. Journal of Political Economy 112, 896-1018.

Kneller, R., Andrew Stevens, P., 2003. The specification of the aggregate production function in the presence of inefficiency. Economics Letters 81(2), 223-226.

Kumbhakar, S. C., Heshmati, A., 1996. Technical change and total factor productivity growth in Swedish manufacturing industries. Econometric Reviews 15(3), 275-298.

Kumbhakar, S. C., Hjalmarsson, L., 1993. Technical Efficiency and Technical Progress in Swedish Dairy Farms. In Chapter 9, Oxford University Press, Oxford, pp. 256-270.

Le, T., Gibson, L. Oxley, L., 2005. Measures of Human Capital: A Review of the Literature, New Zealand Treasury Working Paper 05/10.

Lee, Y.H., Schmidt, P., 1993. A production frontier model with flexible temporal variation in technical inefficiency. Chapter 8 in Fried, H. O., Lovell, C. A. K., Schmidt, S. S. (Eds.), The measurement of productive efficiency: techniques and applications. Oxford University Press, Oxford.

Lim, D., 1980. The incentives and resource utilization in a small, less developed country. Australian Economic Papers 19, 22-30.

Lucas, R. R. J., 1988. On the mechanics of economic development. Journal of Monetary Economics 22, 3-42.

Mahadevan, R., Kalirajan, K., 2000. Singapore's manufacturing sector's TFP growth: A decomposition analysis. Journal of Comparative Economics 28(4), 828-839.

Monte, A. D., Pagagni, E., 2003. R\&D and the growth of firms: empirical analysis of a panel of Italian firms. Research Policy 32(6), 1003-1014.

Nickell, S., 1996. Competition and corporate performance. Journal of Political Economy 104, 724-746.

Nishimitzu, M., Page, Jr., J. M., 1982. Total Factor Productivity Growth, Technological Progress and Technical Efficiency Change: Dimensions of Productivity Change in Yugoslavia, 1965-78. Economic Journal 92 (368) 920-936.

OECD, 2003. The Source of Economic Growth in OECD Countries. OECD, Paris, France. 
Romer, P. M., 1986. Increasing returns and long-run growth. Journal of Political Economy 94 (2), 1002-1037.

Simar, L., 2003. Detecting outliers in frontier models: A simple approach. Journal of Productivity Analysis 20 (3), 391-424.

Sheehan, M., 1997. The evolution of technical efficiency in the Northern Ireland manufacturing sector. Scottish Journal of Political Economy 44(1), 59-81.

Solow, R. M., 1957. Technical Change and the Aggregate Production Function. Review of Economics and Statistics 39 (3), 312-320. 


\section{Appendix}

A.1. Acronym of Industrial sectors

Table A. 1. Acronym of industrial sectors

\begin{tabular}{lll}
\hline Acronym & Explanation & 2-digits SNI \\
FOOD & Food products beverages and tobacco & $15-16$ \\
TXTL & Textile and textile products, leather products & $17-19$ \\
WOOD & Wood and wood products & 20 \\
PULP & Pulp, paper, paper products; publishing and printing & $21-22$ \\
COKE & Coke, refined petroleum products, chemicals, rubber and plastic & $23-25$ \\
& products & \\
NMTL & Non-metallic mineral products & 26 \\
METL & Basic metals and fabricated metal products & $27-28$ \\
MCHN & Machinery and equipment n.e.c & 29 \\
ELEC & Electrical and optical equipment & $30-33$ \\
TRAN & Transport equipment & $34-35$ \\
MNEC & Manufacturing n.e.c & $36-37$ \\
EGWS & Electricity, gas and water supply & $40-41$ \\
WHOL & Wholesale and retail trade; repair of motor vehicles, motorcycles and & $50-52$ \\
& personal and household goods & \\
TSCO & Transport, storage and communication & $60-64$ \\
ESTT & Renting and business activities & $71-74$ \\
\hline
\end{tabular}




\section{List of Tables}

Table 1. Descriptive statistics of variables used in this study

Table 2. Descriptive statistics by size and technology level

\begin{tabular}{|c|c|c|c|c|c|c|c|c|c|}
\hline & \multicolumn{2}{|c|}{$\mathrm{Y}$} & \multicolumn{2}{|c|}{$\mathrm{K}$} & \multicolumn{2}{|c|}{$\mathrm{L}$} & \multirow[t]{2}{*}{ Number } & \multirow{2}{*}{$\begin{array}{c}\text { Percent } \\
(\%)\end{array}$} & \multirow{2}{*}{$\begin{array}{c}\text { Cum Per. } \\
(\%)\end{array}$} \\
\hline & Mean & S.D. & Mean & S.D. & Mean & S.D. & & & \\
\hline \multicolumn{10}{|l|}{ A. By size } \\
\hline Micro & 12 & 1562.5 & 40.3 & 526.1 & 5.5 & 1539.7 & 373 & 0.99 & 0.99 \\
\hline Small & 13.1 & 534.7 & 13.7 & 574.2 & 29.6 & 826.7 & 20643 & 54.56 & 55.54 \\
\hline Small-medium & 29.9 & 164 & 27.2 & 161.2 & 69.9 & 332.9 & 7504 & 19.83 & 75.37 \\
\hline Medium & 77.8 & 214.4 & 72.5 & 316.9 & 168.7 & 369.7 & 5903 & 15.60 & 90.97 \\
\hline Large & 592.6 & 557.6 & 655.4 & 996 & 1140.1 & 948.3 & 3415 & 9.03 & 100.00 \\
\hline \multicolumn{10}{|l|}{ B. By Sector } \\
\hline Manufacturing sector & 77.9 & 401.4 & 69.7 & 378.2 & 162.1 & 5.8 & 24538 & 64.85 & - \\
\hline High tech & 334.3 & 1562.5 & 162.9 & 526.1 & 556.3 & 1539.7 & 546 & 1.45 & - \\
\hline High-medium tech & 117.6 & 534.7 & 96.8 & 574.2 & 230.6 & 826.7 & 6752 & 17.85 & - \\
\hline Medium-low tech & 43.8 & 164 & 36.5 & 161.2 & 108 & 332.9 & 8288 & 21.91 & - \\
\hline Low tech & 63.9 & 214.4 & 74.2 & 316.9 & 136.5 & 369.7 & 8952 & 23.66 & - \\
\hline Service sector & 80.5 & 557.6 & 109.7 & 996 & 154.1 & 948.3 & 13300 & 35.15 & - \\
\hline
\end{tabular}

Table 3. Descriptive statistics of variables used in this study by year

\begin{tabular}{rrrrrrr}
\hline & \multicolumn{3}{c}{ Value added } & \multicolumn{1}{c}{ Capital } & \multicolumn{1}{c}{ Labor } \\
\cline { 2 - 7 } & Mean & S.D. & Mean & \multicolumn{1}{l}{ S.D. } & Mean & \multicolumn{1}{c}{ S.D. } \\
\hline 1992 & 71.9 & 268.7 & 84.8 & 766.9 & 189.2 & 631 \\
1993 & 72.2 & 288.1 & 82.9 & 681.7 & 171.4 & 559.7 \\
1994 & 90.9 & 470.3 & 86.2 & 655.6 & 195.2 & 1034.9 \\
1995 & 90 & 439.3 & 84.7 & 620.4 & 185.7 & 945.6 \\
1996 & 63.6 & 402.2 & 68.4 & 568.8 & 139.8 & 815.3 \\
1997 & 71.3 & 430.5 & 79.2 & 629.1 & 141.7 & 650.5 \\
1998 & 76.9 & 438.3 & 85.1 & 659 & 147.1 & 621.6 \\
1999 & 82.4 & 512.1 & 89.8 & 677.8 & 149.7 & 607.1 \\
2000 & 93.3 & 665.6 & 94.8 & 749.8 & 156.2 & 664.7 \\
\hline
\end{tabular}


Table 4. Elasticity and returns to scale: TT3 and GI3

\begin{tabular}{|c|c|c|c|c|c|c|}
\hline & \multicolumn{3}{|c|}{ TT3 } & \multicolumn{3}{|c|}{ GI3 } \\
\hline & Capital & Labor & RTS & Capital & Labor & RTS \\
\hline \multicolumn{7}{|l|}{ A. By year } \\
\hline 1993 & 0.195 & 0.813 & 1.005 & 0.190 & 0.832 & 1.017 \\
\hline 1994 & 0.194 & 0.815 & 1.007 & 0.190 & 0.832 & 1.018 \\
\hline 1995 & 0.196 & 0.816 & 1.009 & 0.191 & 0.828 & 1.016 \\
\hline 1996 & 0.185 & 0.826 & 1.006 & 0.180 & 0.830 & 1.006 \\
\hline 1997 & 0.194 & 0.818 & 1.009 & 0.191 & 0.821 & 1.009 \\
\hline 1998 & 0.199 & 0.815 & 1.012 & 0.194 & 0.816 & 1.008 \\
\hline 1999 & 0.205 & 0.812 & 1.014 & 0.201 & 0.811 & 1.010 \\
\hline 2000 & 0.210 & 0.809 & 1.017 & 0.208 & 0.806 & 1.012 \\
\hline \multicolumn{7}{|l|}{ B. By industry } \\
\hline FOOD & 0.262 & 0.751 & 1.013 & 0.268 & 0.735 & 1.003 \\
\hline TXTL & 0.200 & 0.800 & 1.000 & 0.186 & 0.818 & 1.003 \\
\hline WOOD & 0.206 & 0.832 & 1.038 & 0.221 & 0.843 & 1.064 \\
\hline PULP & 0.167 & 0.857 & 1.022 & 0.155 & 0.877 & 1.030 \\
\hline COKE & 0.245 & 0.784 & 1.029 & 0.245 & 0.776 & 1.020 \\
\hline NMTL & 0.245 & 0.776 & 1.019 & 0.239 & 0.763 & 1.000 \\
\hline METL & 0.220 & 0.774 & 0.993 & 0.195 & 0.811 & 1.004 \\
\hline MCHN & 0.127 & 0.904 & 1.026 & 0.116 & 0.910 & 1.022 \\
\hline ELEC & 0.190 & 0.843 & 1.032 & 0.172 & 0.850 & 1.021 \\
\hline TRAN & 0.166 & 0.851 & 1.014 & 0.160 & 0.854 & 1.011 \\
\hline MNEC & 0.194 & 0.822 & 1.015 & 0.176 & 0.847 & 1.022 \\
\hline EGWS & 0.346 & 0.669 & 1.016 & 0.366 & 0.647 & 1.013 \\
\hline WHOL & 0.112 & 0.905 & 1.010 & 0.101 & 0.914 & 1.005 \\
\hline TSCO & 0.201 & 0.815 & 1.011 & 0.214 & 0.802 & 1.013 \\
\hline ESTT & 0.183 & 0.794 & 0.973 & 0.184 & 0.792 & 0.974 \\
\hline \multicolumn{7}{|l|}{ C. By size } \\
\hline Micro & 0.196 & 0.814 & 0.994 & 0.197 & 0.812 & 0.992 \\
\hline Small & 0.187 & 0.822 & 1.006 & 0.183 & 0.828 & 1.007 \\
\hline Small-medium & 0.196 & 0.817 & 1.011 & 0.192 & 0.823 & 1.013 \\
\hline Medium & 0.210 & 0.806 & 1.014 & 0.205 & 0.813 & 1.016 \\
\hline Large & 0.235 & 0.788 & 1.021 & 0.229 & 0.795 & 1.023 \\
\hline \multicolumn{7}{|l|}{ D. By sector } \\
\hline $\begin{array}{l}\text { Manufacturing industry } \\
\text { By technology }\end{array}$ & 0.193 & 0.842 & 1.030 & 0.177 & 0.849 & 1.022 \\
\hline High tech & 0.170 & 0.859 & 1.026 & 0.160 & 0.863 & 1.020 \\
\hline High-medium tech & 0.218 & 0.788 & 1.005 & 0.201 & 0.810 & 1.009 \\
\hline Medium-low tech & 0.204 & 0.818 & 1.022 & 0.204 & 0.827 & 1.029 \\
\hline Low tech & 0.193 & 0.808 & 0.996 & 0.198 & 0.802 & 0.996 \\
\hline Service industry & 0.170 & 0.859 & 1.026 & 0.160 & 0.863 & 1.020 \\
\hline \multicolumn{7}{|l|}{ E. By sample } \\
\hline Average & 0.197 & 0.816 & 1.010 & 0.193 & 0.821 & 1.011 \\
\hline Standard deviation & 0.078 & 0.078 & 0.023 & 0.078 & 0.079 & 0.025 \\
\hline
\end{tabular}


Table 5. Rate of technical change and its components: TT3 and GI3

\begin{tabular}{|c|c|c|c|c|c|c|}
\hline & \multicolumn{3}{|c|}{ TT3 } & \multicolumn{3}{|c|}{ GI3 } \\
\hline & Pure & Non-neutral & TCH & Pure & Non-neutral & $\mathrm{TCH}$ \\
\hline \multicolumn{7}{|l|}{ A. By Year } \\
\hline 1993 & 0.025 & 0.001 & 0.026 & 0.003 & 0.021 & 0.025 \\
\hline 1994 & 0.023 & 0.000 & 0.023 & 0.083 & -0.001 & 0.082 \\
\hline 1995 & 0.020 & 0.000 & 0.020 & 0.031 & -0.016 & 0.016 \\
\hline 1996 & 0.018 & 0.000 & 0.018 & 0.002 & -0.023 & -0.021 \\
\hline 1997 & 0.015 & 0.000 & 0.015 & -0.002 & 0.015 & 0.014 \\
\hline 1998 & 0.013 & 0.000 & 0.013 & 0.044 & -0.025 & 0.019 \\
\hline 1999 & 0.011 & 0.000 & 0.010 & 0.008 & 0.008 & 0.015 \\
\hline 2000 & 0.008 & 0.000 & 0.008 & 0.019 & 0.011 & 0.030 \\
\hline \multicolumn{7}{|l|}{ B. By industry } \\
\hline FOOD & -0.048 & 0.052 & 0.003 & 0.021 & -0.015 & 0.006 \\
\hline TXTL & -0.008 & 0.022 & 0.014 & 0.022 & -0.005 & 0.017 \\
\hline WOOD & 0.019 & -0.015 & 0.004 & 0.021 & -0.005 & 0.017 \\
\hline PULP & 0.053 & -0.035 & 0.018 & 0.023 & 0.007 & 0.031 \\
\hline COKE & -0.015 & 0.026 & 0.011 & 0.022 & -0.007 & 0.015 \\
\hline NMTL & -0.025 & 0.043 & 0.018 & 0.021 & -0.009 & 0.013 \\
\hline METL & 0.007 & 0.011 & 0.018 & 0.021 & -0.002 & 0.019 \\
\hline $\mathrm{MCHN}$ & 0.075 & -0.044 & 0.031 & 0.024 & 0.010 & 0.034 \\
\hline ELEC & -0.017 & 0.032 & 0.015 & 0.022 & -0.004 & 0.018 \\
\hline TRAN & 0.049 & -0.022 & 0.026 & 0.023 & 0.003 & 0.026 \\
\hline MNEC & 0.006 & 0.008 & 0.014 & 0.022 & -0.001 & 0.021 \\
\hline EGWS & 0.040 & -0.032 & 0.009 & 0.023 & -0.008 & 0.015 \\
\hline WHOL & 0.064 & -0.039 & 0.025 & 0.021 & 0.005 & 0.026 \\
\hline TSCO & 0.011 & -0.003 & 0.008 & 0.019 & -0.005 & 0.014 \\
\hline ESTT & 0.005 & 0.018 & 0.023 & 0.019 & -0.004 & 0.015 \\
\hline \multicolumn{7}{|l|}{ C. By size } \\
\hline Micro & 0.016 & 0.005 & 0.020 & 0.017 & -0.004 & 0.013 \\
\hline Small & 0.015 & -0.001 & 0.015 & 0.020 & -0.002 & 0.018 \\
\hline Small-medium & 0.017 & -0.001 & 0.017 & 0.022 & -0.002 & 0.020 \\
\hline Medium & 0.018 & 0.001 & 0.019 & 0.023 & -0.002 & 0.021 \\
\hline Large & 0.018 & 0.004 & 0.021 & 0.023 & -0.002 & 0.021 \\
\hline \multicolumn{7}{|l|}{ D.By sector } \\
\hline $\begin{array}{l}\text { Manufacturing industry } \\
\text { By technology }\end{array}$ & 0.015 & 0.002 & 0.016 & 0.022 & -0.001 & 0.021 \\
\hline High tech & -0.009 & 0.028 & 0.020 & 0.022 & -0.003 & 0.019 \\
\hline High-medium tech & 0.035 & -0.012 & 0.024 & 0.023 & 0.003 & 0.026 \\
\hline Medium-low tech & 0.001 & 0.015 & 0.016 & 0.021 & -0.003 & 0.018 \\
\hline Low tech & 0.013 & -0.002 & 0.011 & 0.022 & -0.003 & 0.019 \\
\hline Service industry & 0.020 & -0.003 & 0.017 & 0.020 & -0.003 & 0.016 \\
\hline \multicolumn{7}{|l|}{ E. By sample } \\
\hline Average & 0.016 & 0.000 & 0.017 & 0.021 & -0.002 & 0.019 \\
\hline Standard deviation & 0.035 & 0.029 & 0.018 & 0.025 & 0.033 & 0.038 \\
\hline
\end{tabular}


Table 6. Overall input bias and scale bias

\begin{tabular}{ccccccc}
\hline & \multicolumn{2}{c}{ Capital } & \multicolumn{2}{c}{ Labor } & \multicolumn{2}{c}{ Scale } \\
\cline { 2 - 7 } & Mean & S.D. & Mean & S.D. & Mean & S.D. \\
\hline TT1 & -0.200 & 0.000 & 0.350 & 0.000 & 0.140 & 0.000 \\
TT2 & -0.200 & 0.000 & 0.480 & 0.000 & 0.280 & 0.000 \\
TT3 & -0.110 & 0.670 & 0.280 & 0.880 & 0.160 & 0.290 \\
GI1 & -0.160 & 1.050 & 0.320 & 1.090 & 0.160 & 1.100 \\
GI2 & 0.980 & 1.040 & 0.990 & 1.320 & 1.970 & 0.670 \\
GI3 & -0.030 & 0.750 & 0.010 & 1.720 & -0.020 & 1.090 \\
\hline
\end{tabular}


Table 7. Mean rate of TFP growth: TT1, TT2, TT3, GI1, GI2, GI3 and Solow Residual (SR)

\begin{tabular}{|c|c|c|c|c|c|c|c|}
\hline & TT1 & TT2 & TT3 & GI1 & GI2 & GI3 & SR \\
\hline \multicolumn{8}{|l|}{ A. Measure by year } \\
\hline 1993 & 0.024 & 0.026 & 0.026 & 0.029 & 0.030 & 0.026 & 0.006 \\
\hline 1994 & 0.022 & 0.022 & 0.023 & 0.083 & 0.083 & 0.083 & 0.067 \\
\hline 1995 & 0.020 & 0.019 & 0.021 & 0.014 & 0.014 & 0.016 & 0.013 \\
\hline 1996 & 0.017 & 0.015 & 0.018 & -0.030 & -0.030 & -0.025 & -0.021 \\
\hline 1997 & 0.015 & 0.013 & 0.015 & 0.014 & 0.014 & 0.014 & 0.005 \\
\hline 1998 & 0.013 & 0.010 & 0.013 & 0.017 & 0.017 & 0.019 & 0.010 \\
\hline 1999 & 0.010 & 0.007 & 0.010 & 0.015 & 0.015 & 0.015 & 0.017 \\
\hline 2000 & 0.008 & 0.004 & 0.008 & 0.031 & 0.031 & 0.030 & 0.025 \\
\hline \multicolumn{8}{|l|}{ B. Measure by industry } \\
\hline FOOD & 0.015 & 0.010 & 0.007 & 0.020 & 0.020 & 0.007 & 0.005 \\
\hline TXTL & 0.016 & 0.011 & 0.011 & 0.019 & 0.018 & 0.017 & 0.012 \\
\hline WOOD & 0.014 & 0.002 & 0.003 & 0.019 & 0.018 & 0.020 & 0.019 \\
\hline PULP & 0.015 & 0.010 & 0.018 & 0.020 & 0.020 & 0.031 & 0.013 \\
\hline COKE & 0.015 & 0.008 & 0.010 & 0.020 & 0.020 & 0.016 & 0.023 \\
\hline NMTL & 0.016 & 0.019 & 0.020 & 0.021 & 0.021 & 0.013 & 0.023 \\
\hline METL & 0.015 & 0.018 & 0.014 & 0.018 & 0.018 & 0.019 & 0.019 \\
\hline MCHN & 0.016 & 0.018 & 0.025 & 0.020 & 0.020 & 0.035 & 0.022 \\
\hline ELEC & 0.016 & 0.010 & 0.015 & 0.019 & 0.020 & 0.020 & 0.012 \\
\hline TRAN & 0.016 & 0.015 & 0.024 & 0.020 & 0.020 & 0.026 & 0.022 \\
\hline MNEC & 0.015 & 0.016 & 0.016 & 0.019 & 0.019 & 0.022 & 0.021 \\
\hline EGWS & 0.010 & 0.003 & 0.010 & 0.017 & 0.018 & 0.016 & 0.009 \\
\hline WHOL & 0.014 & 0.006 & 0.018 & 0.018 & 0.019 & 0.026 & -0.002 \\
\hline TSCO & 0.014 & 0.009 & 0.010 & 0.017 & 0.017 & 0.016 & 0.006 \\
\hline ESTT & 0.015 & 0.022 & 0.023 & 0.019 & 0.020 & 0.012 & 0.011 \\
\hline \multicolumn{8}{|l|}{ C. Measure by size } \\
\hline Micro & 0.002 & -0.009 & 0.016 & 0.011 & 0.011 & 0.018 & 0.249 \\
\hline Small & 0.013 & 0.010 & 0.013 & 0.017 & 0.017 & 0.019 & 0.016 \\
\hline Small-medium & 0.015 & 0.013 & 0.016 & 0.020 & 0.020 & 0.020 & 0.001 \\
\hline Medium & 0.017 & 0.016 & 0.018 & 0.022 & 0.022 & 0.021 & 0.014 \\
\hline Large & 0.019 & 0.020 & 0.021 & 0.025 & 0.025 & 0.022 & 0.020 \\
\hline \multicolumn{8}{|l|}{ D. Measure by sector } \\
\hline Manufacturing industry & 0.015 & 0.012 & 0.015 & 0.019 & 0.019 & 0.022 & 0.017 \\
\hline High tech & 0.017 & 0.013 & 0.020 & 0.021 & 0.021 & 0.021 & 0.014 \\
\hline High-medium tech & 0.016 & 0.014 & 0.020 & 0.020 & 0.020 & 0.027 & 0.020 \\
\hline Medium-low tech & 0.015 & 0.016 & 0.014 & 0.019 & 0.019 & 0.019 & 0.020 \\
\hline Low tech & 0.015 & 0.008 & 0.011 & 0.019 & 0.019 & 0.021 & 0.013 \\
\hline Service industry & 0.014 & 0.013 & 0.016 & 0.018 & 0.019 & 0.016 & 0.007 \\
\hline \multicolumn{8}{|l|}{ E. Sample } \\
\hline Average & 0.015 & 0.013 & 0.015 & 0.019 & 0.019 & 0.020 & 0.014 \\
\hline Standard deviation & 0.007 & 0.017 & 0.017 & 0.031 & 0.032 & 0.038 & 0.236 \\
\hline
\end{tabular}


Table 8. Results of second regression on TFP $(n=31505)$

\begin{tabular}{|c|c|c|c|c|c|c|c|}
\hline & Expected sign & TT1 & $T T 2$ & TT3 & GII & GI2 & GI3 \\
\hline Intercept & & $1.32 \mathrm{e}-02 * * *$ & $2.31 \mathrm{e}-03^{*}$ & $1.77 \mathrm{e}-02 * * *$ & $2.43 \mathrm{e}-02 * * *$ & $2.37 \mathrm{e}-02 * * * *$ & $1.33 \mathrm{e}-02 * * *$ \\
\hline CAPINT & $(+/-)$ & $-1.02 \mathrm{e}-03 * * *$ & $-3.08 \mathrm{e}-03 * * *$ & $-1.13 \mathrm{E}-04$ & $-3.63 \mathrm{e}-03 * * *$ & $-3.70 \mathrm{e}-03 * * *$ & $-3.73 \mathrm{E}-04$ \\
\hline MKTCOM & $(+/-)$ & $1.32 \mathrm{e}+00 * * *$ & $1.21 \mathrm{E}+00$ & $3.09 \mathrm{e}+00 * * *$ & $-4.40 \mathrm{e}+00 * * *$ & $-3.98 \mathrm{e}+00 * * *$ & $1.55 \mathrm{E}+00$ \\
\hline HMNCAP & $(+)$ & $8.70 \mathrm{e}-05^{* * *}$ & $1.15 \mathrm{e}-03^{* * *}$ & $1.01 \mathrm{e}-03^{* * *}$ & $2.01 \mathrm{e}-03^{* * *}$ & $1.72 \mathrm{e}-03 * * *$ & $5.30 \mathrm{e}-04 * * *$ \\
\hline HMNGRT & $(+)$ & $-2.31 \mathrm{E}-05$ & $1.02 \mathrm{E}-04$ & $1.67 \mathrm{E}-04$ & $7.50 \mathrm{E}-05$ & $1.09 \mathrm{E}-04$ & $4.12 \mathrm{e}-04 *$ \\
\hline CAPSTR & $(+)$ & $6.22 \mathrm{E}-08$ & 4.61E-07 & $9.76 \mathrm{E}-07$ & $6.54 \mathrm{E}-07$ & $6.65 \mathrm{E}-07$ & $-8.30 \mathrm{E}-07$ \\
\hline WGGRTH & $(+)$ & $1.59 \mathrm{e}-04 * * *$ & $2.85 \mathrm{e}-04 * * *$ & $2.01 \mathrm{e}-04 * * *$ & $2.30 \mathrm{e}-04 * * *$ & $2.24 \mathrm{e}-04 * * *$ & $2.55 \mathrm{e}-04 * * *$ \\
\hline Size dummy included & & Yes & Yes & Yes & Yes & Yes & Yes \\
\hline Year dummy included & & Yes & Yes & Yes & Yes & Yes & Yes \\
\hline Industry dummy included & & Yes & Yes & Yes & Yes & Yes & Yes \\
\hline $\mathrm{R} 2$ & & 0.645 & 0.341 & 0.273 & 0.695 & 0.672 & 0.654 \\
\hline Adjusted R2 & & 0.645 & 0.34 & 0.273 & 0.695 & 0.672 & 0.652 \\
\hline
\end{tabular}

Note: 1 . The dependent variable of each regression model is the rate of TFP growth for each model specification. 